\title{
Are Referral Centers for Non-Muscle-Invasive Bladder Cancer Compliant to EAU Guidelines? A Report from the Vesical Antiblastic Therapy Italian Study
}

\author{
Paolo Gontero ${ }^{\mathrm{a}}$ Marco Oderda $^{\mathrm{a}}$ Vincenzo Altieri ${ }^{\mathrm{b}}$ Riccardo Bartoletti ${ }^{\mathrm{c}}$ \\ Tommaso Caic Renzo Colombo ${ }^{d}$ Antonio Curotto ${ }^{e}$ Savino Di Stasi ${ }^{f}$ \\ Massimo Maffezzinig Vincenzo Serretta ${ }^{h}$ Filippo Sogni ${ }^{i}$ Carlo Terrone $^{i}$ \\ Alessandro Tizzani $^{\mathrm{a}}$ Giuseppe Morgia $^{\mathrm{j}}$ Vincenzo Mirone ${ }^{\mathrm{b}}$ Giorgio Carmignani ${ }^{\mathrm{e}}$ \\ a Urologia 1, Università degli Studi di Torino, Torino, ${ }^{b}$ Clinica Urologica, Università Federico II di Napoli, Napoli, \\ ${ }^{c}$ Clinica Urologica, Università di Firenze, Firenze, ${ }^{d}$ Urologia, Ospedale San Raffaele, Milano, e Clinica Urologica, \\ Ospedale San Martino di Genova, Genova, ${ }^{\mathrm{f} C l i n i c a}$ Urologica, Università di Tor Vergata, Roma, ${ }^{9}$ Urologia, Ospedale

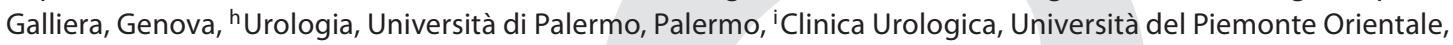 \\ Novara, and ${ }^{\mathrm{j} C l i n i c a}$ Urologica, Università di Catania, Catania, Italy
}

\section{Key Words}

Bladder cancer · Intravesical therapy • EAU guidelines •

Non-muscle-invasive bladder cancer

\begin{abstract}
Introduction: Adherence to international guidelines is viewed as a prerequisite for optimal medical care delivery. Previously reported surveys for non-muscle-invasive bladder cancer (NMIBC) employed mailed questionnaires to urologists or patients resulting in conflicting degrees of agreement with existing guidelines. In the current study, contemporary information on the management of NMIBC was generated from a sample of Italian centers. Patients and Methods: Eight Italian referral centers for the treatment of NMIBC were asked to collect information relative to all consecutive patients with a histology-proven NMIBC undergoing a transurethral resection from January 1 to March 31, 2009. The primary study objective was to verify the level of adherence of disease management with European guidelines. Results: 344 patients resulted in being evaluable.
\end{abstract}

\section{KARGER}

Fax +4161306 1234

E-Mail karger@karger.ch

www.karger.com
(C) 2011 S. Karger AG, Basel

$0042-1138 / 11 / 0000-0000 \$ 38.00 / 0$

Accessible online at:

www.karger.com/uin
$49.2 \%$ of high-risk patients underwent a repeat transurethral resection. Bacillus Calmette-Guérin was employed in 35\% of cases, while chemotherapy was in $22 \%$. An early single regimen was adopted in 136 patients and only in 1 out of 3 lowrisk patients. High-risk NMIBC received bacillus CalmetteGuérin and chemotherapy as first-line therapy in 66 and $12.5 \%$ respectively. After 3 months, cystoscopy had been reported for $82.5 \%$ of patients with a recurrence rate of $13 \%$. Conclusion: Adherence of Italian Institutions to EAU guidelines was optimal when reporting baseline variables. Significant degrees of discrepancy emerged in treatment choices.

Copyright $\odot 2011$ S. Karger AG, Basel

\section{Introduction}

Knowledge of pattern of care of diseases is an important source of information for assessing the quality of care of a health system. In modern medicine, disease management should adhere to evidence-based medicine where possible. For this reason, guidelines have been developed

Paolo Gontero, MD

University of Turin, Urologia 1, Molinette Hospital

C.so Dogliotti 14, IT-10126 Torino (Italy)

Tel. +39011 633 5581, Fax +39011 6334202

E-Mail paolo.gontero@unito.it 
Table 1. Baseline patients and disease characteristics at the time of study entry TUR $(\mathrm{n}=344)$

\begin{tabular}{|c|c|}
\hline Variable & Value \\
\hline \multicolumn{2}{|l|}{ Age, years } \\
\hline Mean & $68.465 \pm 10.08$ \\
\hline Median & 68 (range $35-94)$ \\
\hline \multicolumn{2}{|l|}{ Sex } \\
\hline Male & $226 / 344(85.29 \%)$ \\
\hline Female & $39 / 344(14.71 \%)$ \\
\hline NA & $79 / 344(22.96 \%)$ \\
\hline \multicolumn{2}{|l|}{ Enrolment by center } \\
\hline Torino & 20 \\
\hline Novara & 26 \\
\hline Milano & 44 \\
\hline Genova (Curotto) & 41 \\
\hline Genova (Maffezzini) & 31 \\
\hline Firenze & 61 \\
\hline Roma & 79 \\
\hline Napoli & 18 \\
\hline Palermo & $24>\square$ \\
\hline Primary & $195 / 344(56.69 \%)$ \\
\hline Recurrent & $149 / 344(43.31 \%)$ \\
\hline Mean previous recurrences & 3 \\
\hline Mean previous follow-up & 4.1 years \\
\hline Recurrence density & 0.92 \\
\hline \multicolumn{2}{|l|}{ Focality } \\
\hline Single & $127 / 340(37.35 \%)$ \\
\hline Multifocal & $213 / 340(62.65 \%)$ \\
\hline NA & $4 / 344(1.16 \%)$ \\
\hline \multicolumn{2}{|l|}{ Lesion size } \\
\hline$<3 \mathrm{~cm}$ & $255 / 300(84.33 \%)$ \\
\hline$\geq 3 \mathrm{~cm}$ & $47 / 300(15.66 \%)$ \\
\hline NA & $44 / 344(12.79 \%)$ \\
\hline \multicolumn{2}{|l|}{ Stage } \\
\hline $\mathrm{Tx}$ & $3 / 344(0.8 \%)$ \\
\hline $\mathrm{Ta}$ & $212 / 344(61.6 \%)$ \\
\hline $\mathrm{T} 1$ & $120 / 344(34.9 \%)$ \\
\hline CIS & $9 / 344(2.6 \%)$ \\
\hline \multicolumn{2}{|l|}{ Grading } \\
\hline \multicolumn{2}{|l|}{ WHO $1972(\mathrm{n}=324)$} \\
\hline G1 & $83(25.61 \%)$ \\
\hline G2 & $161(49.69 \%)$ \\
\hline G3 & $80(24.69 \%)$ \\
\hline \multicolumn{2}{|l|}{ ISUP $1998(\mathrm{n}=90)$} \\
\hline PNLMP & $6(6.66 \%)$ \\
\hline Low grade & $33(36.66 \%)$ \\
\hline High grade & $51(56.66 \%)$ \\
\hline \multicolumn{2}{|l|}{ EAU risk category } \\
\hline Low & $67(19.48 \%)$ \\
\hline Intermediate & $153(44.48 \%)$ \\
\hline High & $124(36.04 \%)$ \\
\hline NA & 0 \\
\hline
\end{tabular}

as recommendations generated after thorough evaluation of the quality of existing literature in a given field by panels of expert clinicians. Non-muscle-invasive bladder cancer (NMIBC) accounts for up to $85 \%$ of all bladder cancers (BC), the latter representing the second most common urological malignancy [1]. In view of the relatively favorable natural history, the high recurrence rate and different intravesical treatment options [2], NMIBCs represent a disease category of relatively complex clinical management. In an attempt to conform clinical practice to the best current level of evidence, the European Guidelines [3] and the American Urological Association (AUA) guidelines [4] for NMIBC have been developed. Both guidelines were recently updated through an extensive Medline literature search. Results have been provided by assigning a level of evidence and grade of recommendation in the EAU guidelines or different grades of statements (standard, recommendation, option) in the AUA guidelines, implying a certain degree of scientific uncertainty resulting in potential variability of approaching disease management by clinicians. There are only few studies addressing pattern of care for BC and these have mainly used mailed questionnaires sent to all practicing urologists of the Netherlands and Flanders [5] or a selected sample of urologists in the USA [6]. Among responders, usually not exceeding $50 \%$, compliance to respective national guidelines was found variable, underlying the need for further implementing current guidelines into clinical practice. Another study employed a random sample of BC patients diagnosed in 1995 from the SEER registry in USA showing wide geographical variability highlighting a lack of consensus in disease management [7].

In the current study we aimed to provide a snapshot of the contemporary management of NMIBC at a sample of Italian referral centers that were initially asked to prospectively enroll all consecutive cases treated within a given time interval without being aware of the exact purpose of the study. In the second part of the study, the same centers were requested to retrospectively provide shortterm follow-up data of the same cohort of patients.

\section{Patients and Methods}

The study design was observational prospective in the first part and retrospective in the second. In December 2009, eight Italian referral centers for the management of NMIBC were asked to insert in a database all pathological and prognostic characteristics relative to all consecutive patients undergoing a transurethral resection (TUR) from January 1 to March 31, 2009, resulting in a biopsyproven NMIBC. Criteria to be considered 'referral center' for the 
Table 2. Treatment type and scheme choice according to the risk group

\begin{tabular}{|c|c|c|c|c|}
\hline Treatment & Overall & Low risk & $\begin{array}{l}\text { Intermediate } \\
\text { risk }\end{array}$ & High risk \\
\hline $\begin{array}{l}\text { None } \\
\text { Chemotherapy type (induction) }\end{array}$ & 120 & $40(33.3 \%)$ & $54(45 \%)$ & $26(21.6 \%)$ \\
\hline MMC & 41 & $3(7.3 \%)$ & $25(60.9 \%)$ & $13(31.7 \%)$ \\
\hline Epirubicin & 24 & $1(4.1 \%)$ & $22(91.6 \%)$ & $1(4.1 \%)$ \\
\hline Gemcitabine & 11 & $0(0 \%)$ & $4(36.3 \%)$ & $7(63.6 \%)$ \\
\hline All & 76 & $4(5.2 \%)$ & $51(67.1 \%)$ & $21(27.6 \%)$ \\
\hline \multicolumn{5}{|l|}{ Chemotherapy scheme } \\
\hline Early single instillation & 136 & $24(17.64 \%)$ & $58(42.64 \%)$ & $54(39.7 \%)$ \\
\hline Early single only ${ }^{1}$ & 28 & $18(64.2 \%)$ & $8(28.5 \%)$ & $2(7.1 \%)$ \\
\hline Induction only & 55 & $2(3.6 \%)$ & $39(70.9 \%)$ & $14(25.4 \%)$ \\
\hline Induction plus maintenance & 21 & $1(4.7 \%)$ & $12(57.1 \%)$ & $8(38.1 \%)$ \\
\hline \multicolumn{5}{|l|}{ BCG } \\
\hline Induction only & 31 & $2(6.4 \%)$ & $5(16.1 \%)$ & $24(77.4 \%)$ \\
\hline Any maintenance & 89 & $3(3.3 \%)$ & $35(39.3 \%)$ & $51(57.3 \%)$ \\
\hline All & 120 & $5(4.1 \%)$ & $40(33.3 \%)$ & $75(62.5 \%)$ \\
\hline
\end{tabular}

${ }^{1}$ Early single only: not followed by induction.

disease were the presence of at least two peer-reviewed publications in the field of NMIBC from an author currently working in the center. Investigators were asked to engage in the first prospective part of the study to test the recruitment potential and accuracy of data collection for future studies. Baseline requested information included sex and age, traditional prognostic factors at the time of enrolment, i.e. stage, grade, association with CIS, size and number of lesions, number of recurrences, yearly recurrence density (the ratio derived from the number of recurrences per year), the highest grade and stage of previous recurrences, and the EAU risk categorization for NMIBC [3]. Investigators were kept unaware of the need of follow-up information for the study purpose. In September, all centers were asked to update their information by completing additional fields of the database with information regarding repeat TUR (any TUR accomplished before 3 months), initial treatment, results of the first follow-up cystoscopy and any planned intravesical maintenance therapy. The centers were requested to update clinical information available at the end of August, resulting in a minimum follow-up time of 5 months. Data were presented with descriptive analysis of the main variables. Primary study objectives were to describe the contemporary management of NMIBC in selected referral centers and to assess their adherence to European guidelines.

\section{Results}

Out of a total of 410 available patients, 66 were excluded for violation of inclusion criteria ( 35 for being T2 and 31 for being T0 at entry TUR) while 344 resulted in being evaluable. The response rate to both questionnaires was $100 \%$. Baseline patients' characteristics are reported in table 1. Data on focality and size of the tumor were provided in 98.8 and $87.2 \%$ respectively, while EAU risk stratification was available in $100 \%$ of cases.

$74(21.5 \%)$ of the whole series underwent a repeat TUR: 64 (86.4\%) were T1 and/or CIS, while 58 (78.4\%) were G3 or high-grade tumors. Figure 1 stratifies the adoption of a repeat TUR by risk category and within each risk category by a primary or a recurrent tumor. Treatment choices in the overall series and within each risk category are summarized in figure 2. The adoption of TUR as sole treatment progressively decreased with increasing the risk category while an opposite trend was observed with BCG. Figure 3 shows the rate of primary and recurrent tumors within each EAU risk group that underwent a specific treatment, while in figure 4 the same data are referred to patients who were treatment-naive, had already received intravesical therapy (except for an early single instillation) or were previously treated with BCG. Absolute numbers and percentage values regarding the type of treatment and scheme are reported in table 2. A follow-up cystoscopy was performed in $82.5 \%$ of patients at 6 months' follow-up.

\section{Discussion}

The present study represents a contemporary snapshot of the management of a consecutive series of NMIBC observed in the first trimester of the year 2009 at seven Ital- 


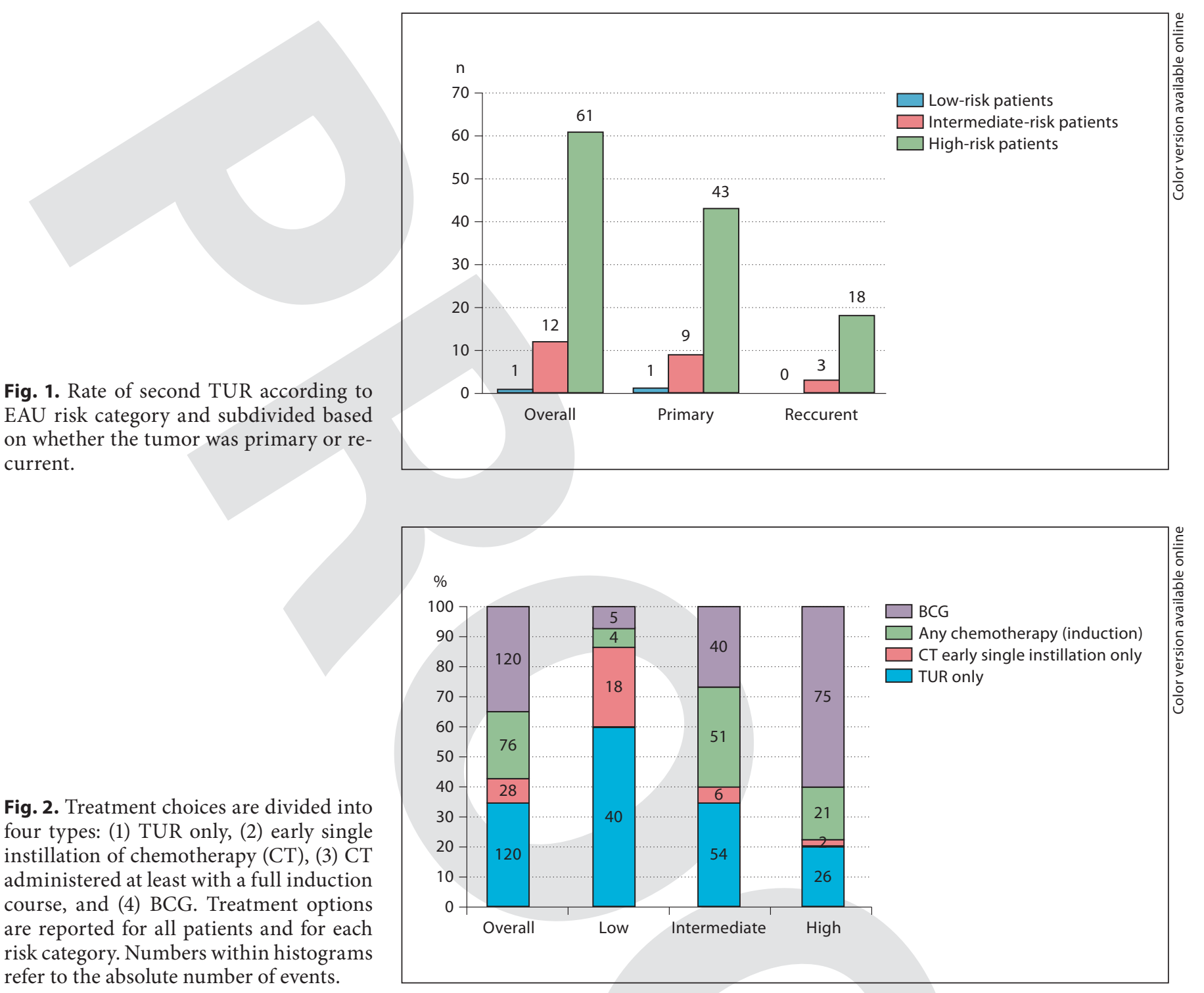

Fig. 1. Rate of second TUR according to EAU risk category and subdivided based on whether the tumor was primary or recurrent.

Fig. 2. Treatment choices are divided into four types: (1) TUR only, (2) early single instillation of chemotherapy (CT), (3) CT administered at least with a full induction course, and (4) BCG. Treatment options are reported for all patients and for each refer to the absolute number of events.

ian institutions. The generated information, other than representing an update of the use of intravesical therapies, provides a hint of the degree of compliance to current guidelines for NMIBC from referral centers within a country of the European Community [3].

The study was originally set as a prospective collection of baseline information on all consecutive NMIBC observed in the selected institutions. The study consisted in a baseline assessment of the accrual potential and accuracy of data collection of each center to be involved in a multicentric national study on NMIBC. After 3 months all centers were asked to retrospectively provide shortterm follow-up information on the same patients to serve for the current pattern of care study. In addition to previous similar studies, this 'two-stage' data collection enabled a more reliable patient-based representation of everyday clinical practice of NMIBC, out of the scenario of a proper clinical study where data reporting is driven by the necessity to adhere to a study protocol. From this perspective, the $100 \%$ response rate to both stages of the study clearly reflects the selection of institutions potentially highly compliant to participate in a clinical study. Previous care assessment patterns conducted in Flanders [5] and the USA [6] employed 'practice-based' rather than 'patient-based' questionnaires and flawed by a less than $50 \%$ response rate. The EAU risk categorization [3], a 


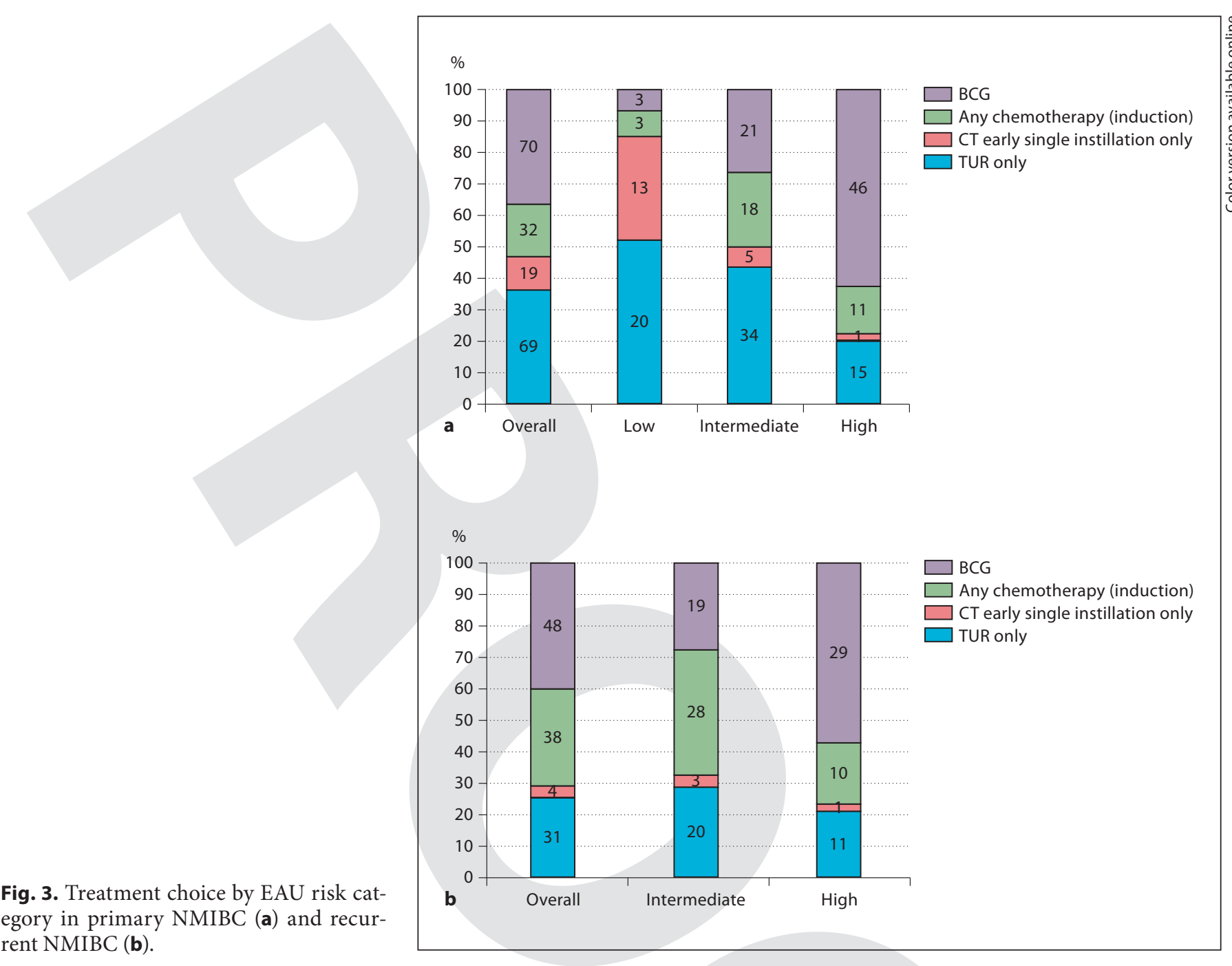

Fig. 4. Rate of treatment choice stratified by being treatment-naive, having previously received some sort of intravesical therapy except for an early single instillation and having previously received BCG respectively. 
mainstay for decision-making in NMIBC, was provided for all 344 evaluable patients.

Repeat TUR within 1 month is highly recommended for all high-risk NMIBC in EAU guidelines [3]. In the current study, only $49.2 \%$ of high-risk patients underwent a repeat TUR, $70.5 \%$ of whom were primary and the remainder recurrent lesions. Whether this may reflect inadequate compliance to the best evidence practice or simply a different view based on scientific ground cannot be addressed by the current study. The concept of repeat TUR remains open to debate. In a recent study, TUR was repeated only in high-grade patients with deep lamina propria invasion (T1b) and safely avoided in cases with T1a disease [8].

Treatment choice in NMIBC is highly dependent from the allocated risk category according to EAU guidelines [3]. In low-risk disease one immediate instillation of chemotherapy is strongly recommended. Compliance to this la recommendation level [9] was surprisingly low in the current series with less than $8 \%$ of the whole group receiving an early instillation and only 1 out of 4 belonging to the low-risk category. A sole TUR remained the most widely adopted treatment option in the low-risk category but it still represented a treatment for up to $20 \%$ of highrisk patients. For this latter category, BCG should represent the treatment choice in view of its ability to reduce the risk of progression [10]. Overall, adoption of BCG immunotherapy at Italian referral centers increased from $25 \%$ in the intermediate-risk category to $60 \%$ in highrisk category. These rates did not change when comparing primary to recurrent intermediate- and high-risk tumors. Since only a minority of patients have absolute contraindication to BCG [11], a 40\% rate of high-risk NMIBC receiving alternative conservative treatment to BCG clearly reflect a different view from current guidelines.

One of the points of strength of the current study is its ability to provide updated information on the pattern of care of NMIBC by employing a methodology of data collection that is rather original and 'patient-based'. By contrast, the results are limited by the low number of cases and institutions, and the short observation period.

\section{Conclusion}

This short-term prospective observation of the management of NMIBC at several institutions considered national referral centers for the disease highlights optimal adherence to European guidelines in terms of baseline data collection but a significant degree of discrepancy from most recommended treatment options.

\section{References}

1 Parker SL, Tong T, Bolden S, Wingo PA: Cancer statistics, 1997. CA Cancer J Clin 1997;47: $5-27$.

2 Malmström PU, Sylvester RJ, Crawford DE, Friedrich M, Krege S, Rintala E, Solsona E, Di Stasi SM, Witjes JA: An individual patient data meta-analysis of the long-term outcome of randomised studies comparing intravesical mitomycin $\mathrm{C}$ versus bacillus CalmetteGuérin for non-muscle-invasive bladder cancer. Eur Urol 2009;56:247-256.

3 Babjuk M, Oosterlinck W, Sylvester R, Kaasinen E, Böhle A, Palou-Redorta J, European Association of Urology (EAU). EAU guidelines on non-muscle-invasive urothelial carcinoma of the bladder. Eur Urol 2008;54: 303-314.

4 Hall MC, Chang SS, Dalbagni G, Pruthi RS, Seigne JD, Skinner EC, Wolf JS Jr, Schellhammer PF: Guideline for the management of non-muscle invasive bladder cancer (stag- es Ta, T1 and Tis): 2007 update. J Urol 2007; 178:2314-2330.

5 Witjes JA, Melissen DO, Kiemeney LA: Current practice in the management of superficial bladder cancer in the Netherlands and Belgian Flanders: a survey. Eur Urol 2006;49: 478-484.

6 Joudi FN, Smith BJ, O’Donnell MA, Konety BR: Contemporary management of superficial bladder cancer in the United States: a pattern of care analysis. Urology 2003;62: 1083-1088.

7 Snyder C, Harlan L, Knopf K, Potosky A, Kaplan R: Patterns of care for the treatment of bladder cancer. J Urol 2003;169:1697-1701.

8 Orsola A, Cecchini L, Raventós CX, Trilla E, Planas J, Landolfi S, de Torres I, Morote J: Risk factors for positive findings in patients with high-grade $\mathrm{T} 1$ bladder cancer treated with transurethral resection of bladder tumour (TUR) and bacilli Calmette-Guérin therapy and the decision for a repeat TUR. BJU Int 2010;105:202-207.

9 Sylvester RJ, Oosterlinck W, van der Meijden AP: A single immediate postoperative instillation of chemotherapy decreases the risk of recurrence in patients with stage Ta T1 bladder cancer: a meta-analysis of published results of randomized clinical trials. J Urol 2004;171:2186-2190, quiz 2435.

10 Sylvester RJ, Van der Meijden AP, Lamm DL: Intravesical bacillus Calmette-Guérin reduces the risk of progression in patients with superficial bladder cancer: a meta-analysis of the published results of randomized clinical trials. J Urol 2002;168:1964-1970.

11 Gontero P, Bohle A, Malmstrom PU, O’Donnell MA, Oderda M, Sylvester R, Witjes F: The role of bacillus CalmetteGuérin in the treatment of non-muscle-invasive bladder cancer. Eur Urol 2010;57:410429. 